\title{
THE GENETICAL ARCHITECTURE OF GENERAL AND SPECIFIC ENVIRONMENTAL SENSITIVITY
}

\author{
V. CONNOLLY* and J. L. JINKS \\ Department of Genetics, University of Birmingham, Birmingham B15 2TT
}

Received 12.iii.75

\begin{abstract}
SUMMARY
The determination of rate of growth in a genetically replicated diallel set of crosses between six dikaryotic selection lines of Schizophyllum commune has been examined at $15^{\circ}, 20^{\circ}, 25^{\circ}$ and $30^{\circ} \mathrm{C}$. Three of the lines had been selected for low growth rate on the basis of their performance at $20^{\circ} \mathrm{C}, 30^{\circ} \mathrm{C}$ or at both temperatures and three for high growth rate on the basis of their performance in one or other of these three environments.

The genetical control of rate of growth itself has been analysed in each of the four environments and in addition the rate of growth of each mating in the four environments has been converted into two components each of which measures a different aspect of sensitivity to temperature; general sensitivity which is a linear function of mean rate of growth and specific sensitivity which is independent of it. From genetical analysis of these two components we have drawn conclusions about the genetical architecture of rate of growth and of its interaction with temperature and about the genetical basis of the differences among the six selection lines.

All are largely explicable in terms of additive and dominance gene action with dominance mainly in the direction of faster growth and greater temperature sensitivity. The interactions between rate of growth and temperature that are independent of rate of growth itself involve epistatic gene interactions that can be traced to changes in the dominance relationships of fast and slow growth rate alleles with temperature. The differences among the three low selections and among the three high selections which can be related to the temperature in which they were selected are due to recessive alleles which are fully expressed only in the temperature of selection.
\end{abstract}

\section{INTRODUGTION}

Dikaryotic lines of Schizophyllum commune selected for high rate of growth on the basis of their performance in good $\left(30^{\circ} \mathrm{C}\right)$, poor $\left(20^{\circ} \mathrm{C}\right)$ or both environments have much the same mean rates of growth when grown in a range of environments $\left(15^{\circ}\right.$ to $\left.35^{\circ} \mathrm{C}\right)$ but they differ in their environmental sensitivities. Those selected for their performance in good environments are more sensitive than those selected for their performance in poor environments while those selected on the basis of both are intermediate. Corresponding low selections behave similarly except that those selected on their performance in a poor environment have the greatest environmental sensitivity, and those selected on their performance in a good environment the least (Jinks and Connolly, 1973, 1975). At the same time all the high selections are more sensitive to the environment than the low selections. Thus differences in sensitivity between the high and low selections are related to their differences in mean performance while the differences among the

* Present Address: Plant Breeding Department, The Agricultural Institute, Oak Park, Carlow, Ireland. 
high selections and among the low selections are a specific interaction between the direction of selection and the environment in which the selection was made.

In the present paper we separate these two components of environmental sensitivity and analyse their genetical control by means of a diallel set of matings among the selection lines raised in a number of environments.

\section{Materials AND MEthoD}

The material is the six selections of isolate 2 of $S$. commune, 2LP, 2LG, $2 \mathrm{~L}, 2 \mathrm{HP}, 2 \mathrm{HG}$ and $2 \mathrm{H}$. Their origin by selection and their properties have been described by Connolly and Simchen (1973) and Jinks and Connolly (1973, 1975). Each selection line was represented in a diallel mating programme by two genetic replicates. These were two sibling monokaryons chosen for their compatibility with one another and with at least one of the two monokaryons chosen to represent each of the other five selection lines. A $6 \times 6$ diallel set of matings (dikaryons) was made between one set of six compatible monokaryons from the six selection lines and a second, replicate diallel set between the other six compatible monokaryons. Each experiment consisted of the 36 matings from each of the two diallels independently randomised and clonally duplicated in each of two blocks. One such experiment of 144 colonies was grown at $15^{\circ}, 20^{\circ}, 25^{\circ}$ and $30^{\circ} \mathrm{C}$, and the rate of growth of each colony determined. Details of the cultural conditions, matings and scoring are given by Simchen and Jinks (1964) and Connolly and Simchen (1973).

\section{Results}

There are in all 72 matings consisting of two independently produced $6 \times 6$ diallels of 36 matings. Of these, six are sib matings within each of the six selection lines and they are in effect the parents of the diallels. The remaining 30 are made up of 15 pairs of reciprocal matings between the six selections. For each of the 72 matings there are duplicate growth rate determinations, one from each of the two blocks, in each of the four temperature environments.

\section{(i) Reciprocal matings}

In $S$. commune reciprocal matings have the same chromosomal gene complement and any difference between them must have its origin in the non-chromosomal material. The latter does not come equally from both mates. When two monokaryons are mated, the chromosomal material of one monokaryon migrates into the intact chromosomal and non-chromosomal complement of its monokaryotic mate. Between a pair of reciprocal matings the roles of the two monokaryons are reversed.

The magnitude of the differences between reciprocal crosses and their consistency over the replicate diallels and duplicate blocks have been examined within each environment by an analysis of variance. The reciprocal differences are significantly greater than the duplicate differences in all four environments but they are sufficiently inconsistent in magnitude 
and sign between the replicate diallels for them to become non-significant on summing over these replicates. The largest component of the reciprocal differences is in fact their interaction with replicates. While there are, therefore, differences between reciprocal crosses their inconsistency over the genetic replicates means that they cannot be ascribed to differences between selection lines which are our principal concern. As a consequence the subsequent analyses of the differences between selection lines have been carried out after pooling reciprocal crosses and duplicate blocks and using differences between the independently replicated diallel sets of crosses to provide estimates of error variance.

\section{(ii) Measurement of environmental sensitivity}

After pooling reciprocal crosses and duplicate blocks we have growth rate determinations in the four temperature environments for two replicate sets of 21 matings, each set consisting of the six parental selections and the 15 matings between them. For each mating the variation in growth rate over the four environments is a measure of its sensitivity to temperature. Past studies of these selections have shown that this variation is almost entirely accounted for by a linear regression on temperature over the range $15^{\circ}$ to $30^{\circ} \mathrm{G}$ (Jinks and Connolly, 1975). In the present study 97.6 per cent of the sum of squares of differences over temperature for each mating is on average accounted for by a linear regression on temperature, the range over the 21 matings being 83 to 100 per cent. The data have, therefore, been reduced to a linear regression coefficient and mean over the four temperatures for each of the 21 matings in each of the two genetic replicates (tables 1 and 2). These will be our measures of sensitivity and mean performance, respectively.

\section{TABLE 1}

Linear regression coefficients for the regression of rate of growth on temperature for each of the 21 matings between the six selections in each of the two genetic replicates after averaging the growth rates in each temperature over duplicates and reciprocal matings

\begin{tabular}{|c|c|c|c|c|c|c|}
\hline & $2 \mathrm{LP}$ & 2LG & $2 \mathrm{~L}$ & $2 \mathrm{HP}$ & $2 \mathrm{HG}$ & $2 \mathrm{H}$ \\
\hline $2 \mathrm{LP}$ & $\begin{array}{l}2 \cdot 430 \\
2 \cdot 340\end{array}$ & $\begin{array}{l}2.425 \\
1.875\end{array}$ & $\begin{array}{l}2 \cdot 785 \\
2 \cdot 550\end{array}$ & $\begin{array}{l}4 \cdot 310 \\
4 \cdot 305\end{array}$ & $\begin{array}{l}4 \cdot 510 \\
4 \cdot 105\end{array}$ & $\begin{array}{l}4 \cdot 725 \\
4 \cdot 260\end{array}$ \\
\hline 2LG & - & $\begin{array}{l}1 \cdot 180 \\
1 \cdot 240\end{array}$ & $\begin{array}{l}0.870 \\
1.610\end{array}$ & $\begin{array}{l}4 \cdot 055 \\
4 \cdot 385\end{array}$ & $\begin{array}{l}4 \cdot 195 \\
4 \cdot 310\end{array}$ & $\begin{array}{l}3 \cdot 880 \\
4 \cdot 625\end{array}$ \\
\hline $2 \mathrm{~L}$ & - & $\overline{-}$ & $\begin{array}{l}1 \cdot 840 \\
1 \cdot 450\end{array}$ & $\begin{array}{l}4 \cdot 550 \\
4 \cdot 220\end{array}$ & $\begin{array}{l}5 \cdot 280 \\
4 \cdot 775\end{array}$ & $\begin{array}{l}5 \cdot 140 \\
4 \cdot 955\end{array}$ \\
\hline $2 \mathrm{HP}$ & $\overline{-}$ & $\overline{-}$ & - & $\begin{array}{l}4 \cdot 270 \\
4 \cdot 400\end{array}$ & $\begin{array}{l}5 \cdot 285 \\
5 \cdot 370\end{array}$ & $\begin{array}{l}5 \cdot 310 \\
5 \cdot 170\end{array}$ \\
\hline $2 \mathrm{HG}$ & - & $\overline{-}$ & $\overline{-}$ & $\overline{-}$ & $\begin{array}{l}5 \cdot 360 \\
5 \cdot 520\end{array}$ & $\begin{array}{l}5 \cdot 510 \\
5 \cdot 450\end{array}$ \\
\hline $2 \mathrm{H}$ & - & $=$ & - & - & - & $\begin{array}{l}5 \cdot 400 \\
5 \cdot 330\end{array}$ \\
\hline
\end{tabular}


TABLE 2

Mean rates of growth after averaging over temperatures, duplicates and reciprocal matings for each of the 21 matings between the six selections in each of the genetic replicates

\begin{tabular}{|c|c|c|c|c|c|c|}
\hline & $2 \mathrm{LP}$ & 2LG & $2 \mathrm{~L}$ & $2 \mathrm{HP}$ & $2 \mathrm{HG}$ & $2 \mathrm{H}$ \\
\hline $2 \mathrm{LP}$ & $\begin{array}{l}36 \cdot 125 \\
35 \cdot 500\end{array}$ & $\begin{array}{l}41 \cdot 563 \\
35 \cdot 938\end{array}$ & $\begin{array}{l}35 \cdot 813 \\
35 \cdot 750\end{array}$ & $\begin{array}{l}57 \cdot 250 \\
55 \cdot 813\end{array}$ & $\begin{array}{l}58 \cdot 375 \\
57 \cdot 063\end{array}$ & $\begin{array}{l}61 \cdot 063 \\
57 \cdot 875\end{array}$ \\
\hline 2LG & - & $\begin{array}{l}34 \cdot 750 \\
34 \cdot 250\end{array}$ & $\begin{array}{l}31 \cdot 500 \\
35 \cdot 625\end{array}$ & $\begin{array}{l}55 \cdot 938 \\
57.438\end{array}$ & $\begin{array}{l}59 \cdot 438 \\
61 \cdot 375\end{array}$ & $\begin{array}{l}58 \cdot 250 \\
62 \cdot 938\end{array}$ \\
\hline $2 \mathrm{~L}$ & - & - & $\begin{array}{l}32 \cdot 750 \\
32 \cdot 375\end{array}$ & $\begin{array}{l}61 \cdot 250 \\
58 \cdot 625\end{array}$ & $\begin{array}{l}67 \cdot 375 \\
63 \cdot 313\end{array}$ & $\begin{array}{l}68 \cdot 250 \\
64 \cdot 313\end{array}$ \\
\hline $2 \mathrm{HP}$ & I & - & - & $\begin{array}{l}70 \cdot 125 \\
71 \cdot 250\end{array}$ & $\begin{array}{l}68 \cdot 188 \\
71 \cdot 000\end{array}$ & $\begin{array}{l}70 \cdot 000 \\
69 \cdot 500\end{array}$ \\
\hline $2 \mathrm{HG}$ & - & - & - & - & $\begin{array}{l}70 \cdot 750 \\
71 \cdot 250\end{array}$ & $\begin{array}{l}74 \cdot 625 \\
72 \cdot 250\end{array}$ \\
\hline $2 \mathrm{H}$ & - & - & - & - & - & $\begin{array}{l}76 \cdot 000 \\
76 \cdot 125\end{array}$ \\
\hline
\end{tabular}

(iii) Partitioning the environmental sensitivities

The regression coefficients (table 1) and their corresponding means (table 2) display all the relationships described in previous papers (Jinks and Connolly, 1973, 1975). All three low selections have a lower than average and all three high selections a higher than average sensitivity to temperature. This pattern also extends to the matings among them. The three matings among the low selections have a lower than average and the three matings among the high selections have a higher than average sensitivity to temperature while the nine matings of high with low selections are intermediate. Equally, the low selections made in the poor environment (2LP) and the high selection made in the good environment (2HG) are more sensitive to temperature than their corresponding low and high selections made in the alternative environment ( $2 \mathrm{LG}$ and $2 \mathrm{HP})$. And again this pattern extends to the matings among them. We can, therefore, recognise the two components of sensitivity noted in our earlier papers. One is the difference in sensitivity between high and low selections which is directly related to the direction of selection and reflected in a high positive correlation between sensitivity and mean performance. The other is the difference in sensitivity among the low selections and among the high selections which is related to the environment of selection and is reflected in a significant interaction between the direction of selection and the quality of the environment used for selection.

To estimate the relationship between the measure of environmental sensitivity and mean performance for these data a regression analysis of the regression coefficients in table 1 on the mean performances in table 2 was carried out jointly for the two genetic replicates. The joint regression was highly significant $(P<0.001)$ with a coefficient of $0.09325 \pm 0.00428$ and the two replicates were homogeneous with coefficients of $0.09344 \pm 0.00644$ and $0.09304 \pm 0.00548$. The sensitivity $\left(y_{i}\right)$ that any mating $i$ is expected to have because of its mean performance $x_{i}$ is, therefore, given by the joint regression equation:

$$
y_{i}=-1 \cdot 317904+0.093252 x_{i} .
$$


The expected sensitivities calculated for each of the matings from the corresponding observed mean performances ( $x_{i}$ values) in table 2 are listed in table 3. The deviations, taking sign into account, of these expected values from those observed (table 1 ) are listed in table 4 . The environmental sensitivity of each mating has now been partitioned into a component,

TABle 3

The expected sensitivities of each of the 21 matings in each of the two genetic replicates. These are the general sensitivities of the matings predicted from their mean rates of growth in table 2

$\begin{array}{lllllll} & \text { 2LP } & \text { 2LG } & 2 \mathrm{~L} & 2 \mathrm{HP} & 2 \mathrm{HG} & 2 \mathrm{H} \\ 2 \mathrm{LP} & 2 \cdot 051 & 2 \cdot 558 & 2 \cdot 022 & 4 \cdot 021 & 4 \cdot 126 & 4 \cdot 376 \\ & 1 \cdot 992 & 2 \cdot 033 & 2 \cdot 016 & 3 \cdot 887 & 4 \cdot 056 & 4 \cdot 079 \\ 2 \mathrm{LG} & - & 1 \cdot 923 & 1 \cdot 620 & 3 \cdot 898 & 4 \cdot 225 & 4 \cdot 114 \\ & - & 1 \cdot 876 & 2 \cdot 004 & 4 \cdot 038 & 4 \cdot 406 & 4 \cdot 551 \\ 2 \mathrm{~L} & - & - & 1 \cdot 736 & 4 \cdot 394 & 4 \cdot 965 & 5 \cdot 046 \\ & - & - & 1 \cdot 701 & 4 \cdot 149 & 4 \cdot 586 & 4 \cdot 680 \\ 2 \mathrm{HP} & - & - & - & 5 \cdot 221 & 5 \cdot 041 & 5 \cdot 210 \\ & - & - & - & 5 \cdot 326 & 5 \cdot 303 & 5 \cdot 163 \\ 2 \mathrm{HG} & - & - & - & - & 5 \cdot 280 & 5 \cdot 641 \\ & - & - & - & - & 5 \cdot 326 & 5 \cdot 420 \\ 2 \mathrm{H} & - & - & - & - & - & 5 \cdot 769 \\ & - & - & - & - & - & 5 \cdot 781\end{array}$

general sensitivity, which reflects only the correlated response to high and low selection (table 3) and a component, specific sensitivity, which reflects the effect of the environment of selection on the sensitivity of the high and low selections and is completely independent of the response to high and low selection (table 4).

\section{TABle 4}

The deviations of the observed (table 1) and expected sensitivities (table 3) for each of the 21 matings in each of the two genetic replicates. These are the specific sensitivities of the matings which are independent of their mean rates of growth in table 2

\begin{tabular}{|c|c|c|c|c|c|c|}
\hline & $2 \mathrm{LP}$ & 2LG & $2 \mathrm{~L}$ & $2 \mathrm{HP}$ & $2 \mathrm{HG}$ & $2 \mathrm{H}$ \\
\hline $2 \mathrm{LP}$ & $\begin{array}{l}0 \cdot 379 \\
0 \cdot 348\end{array}$ & $\begin{array}{l}-0.133 \\
-0.158\end{array}$ & $\begin{array}{l}0 \cdot 764 \\
0 \cdot 534\end{array}$ & $\begin{array}{l}0.289 \\
0.418\end{array}$ & $\begin{array}{l}0 \cdot 384 \\
0 \cdot 049\end{array}$ & $\begin{array}{l}0 \cdot 349 \\
0 \cdot 181\end{array}$ \\
\hline 2LG & - & $\begin{array}{l}-0.743 \\
-0.636\end{array}$ & $\begin{array}{l}-0.750 \\
-0.394\end{array}$ & $\begin{array}{l}0 \cdot 157 \\
0 \cdot 347\end{array}$ & $\begin{array}{l}-0.030 \\
-0.096\end{array}$ & $\begin{array}{r}-0.234 \\
0.074\end{array}$ \\
\hline $2 \mathrm{~L}$ & - & - & $\begin{array}{r}0 \cdot 104 \\
-0 \cdot 251\end{array}$ & $\begin{array}{l}0 \cdot 156 \\
0 \cdot 071\end{array}$ & $\begin{array}{l}0 \cdot 315 \\
0 \cdot 189\end{array}$ & $\begin{array}{l}0.094 \\
0.276\end{array}$ \\
\hline $2 \mathrm{HP}$ & - & - & - & $\begin{array}{l}-0.951 \\
-0.926\end{array}$ & $\begin{array}{l}-0.244 \\
-0.067\end{array}$ & $\begin{array}{l}0 \cdot 100 \\
0.007\end{array}$ \\
\hline $2 \mathrm{HG}$ & - & - & - & - & $\begin{array}{l}0 \cdot 080 \\
0 \cdot 194\end{array}$ & $\begin{array}{r}-0.131 \\
0.030\end{array}$ \\
\hline $2 \mathbf{H}$ & - & - & - & - & - & $\begin{array}{l}-0.369 \\
-0.451\end{array}$ \\
\hline
\end{tabular}




\section{(iv) Diallel analysis of general and specific environmental sensitivity}

The general and specific environmental sensitivities of the replicated diallel sets of crosses have been subjected to the analysis of Jinks (1954) and Hayman (1954) as described by Mather and Jinks (1971). The standard analysis of variance of replicated, half diallel tables showed highly significant additive and non-additive genetical variation for both general and specific sensitivity. Since the matings between selections have greater general and specific sensitivities on average than the parental selection lines themselves (tables 3 and 4) it is not surprising that this non-additive variation has a significant directional component which confers greater sensitivity of both kinds. The relationships between the variances $(V r)$ and covariances $(W r$ ) of arrays (tables 5 and 6 ) have been examined for both kinds of sensitivity to investigate the nature of this non-additive variation.

\section{TABLE 5}

The variances $(\mathrm{Vr})$ and covariances $(\mathrm{Wr})$ for the six arrays of the half diallel table of general sensitivities (table 3) for each of the two genetic replicates

\begin{tabular}{lccccc}
\multirow{2}{*}{ Array } & \multicolumn{2}{c}{ Replicate 1 } & & \multicolumn{2}{c}{ Replicate 2 } \\
2LP & 1.207 & 2.099 & & $1 \cdot 208$ & $2 \cdot 172$ \\
2LG & 1.358 & $2 \cdot 194$ & & 1.703 & 2.585 \\
2L & 2.785 & 3.215 & & $2 \cdot 018$ & $2 \cdot 815$ \\
2HP & 0.363 & 1.103 & & 0.471 & 1.330 \\
2HG & 0.354 & 0.939 & & 0.331 & 1.078 \\
2H & 0.444 & 1.088 & & 0.389 & 1.119
\end{tabular}

TABLE 6

The variances $(\mathrm{Vr})$ and covariances $(\mathrm{Wr})$ for the six arrays of the half diallel table of specific sensitivities (table 4) for each of the two genetic replicates

\begin{tabular}{|c|c|c|c|c|}
\hline \multirow[b]{2}{*}{ Array } & \multicolumn{2}{|c|}{ Replicate 1} & \multicolumn{2}{|c|}{ Replicate 2} \\
\hline & $V r$ & $W r$ & $V r$ & $W r$ \\
\hline 2LP & 0.082 & 0.091 & 0.066 & 0.004 \\
\hline 2LG & $0 \cdot 142$ & -0.015 & 0.119 & -0.035 \\
\hline $2 \mathrm{~L}$ & 0.242 & $0 \cdot 174$ & $0 \cdot 118$ & 0.094 \\
\hline $2 \mathrm{HP}$ & 0.213 & 0.147 & $0 \cdot 232$ & $0 \cdot 141$ \\
\hline $2 \mathrm{HG}$ & 0.062 & $0 \cdot 116$ & 0.015 & $0 \cdot 040$ \\
\hline $2 \mathrm{H}$ & 0.069 & 0.060 & 0.063 & 0.037 \\
\hline
\end{tabular}

For general sensitivity the joint analysis of the replicates shows that there are highly significant differences between arrays for the sum of $W r+V r(\mathrm{P}<0 \cdot 001)$ but no significant differences for the difference $W r-V r$ $(P>0 \cdot 05)$. Furthermore, the sums are highly negatively correlated with the means of the arrays $(r=-0 \cdot 8830)$. From these analyses we can conclude that the non-additive variation is due to dominant rather than epistatic gene action, that the selection lines differ in the proportion of dominant to recessive alleles they carry, and that the alleles conferring greater sensitivity are dominant to those conferring lesser sensitivity. The order of the 
selection lines from the highest to the lowest proportion of dominant alleles is $2 \mathrm{HG}, 2 \mathrm{H}, 2 \mathrm{HP}, 2 \mathrm{LP}, 2 \mathrm{LG}, 2 \mathrm{~L}$, which apart from the last two is the order from the most to the least sensitive. All the evidence is therefore consistent in showing that general environmental sensitivity is dominant to insensitivity.

Although there is no significant non-linearity in the relationship between $W r$ and $V r$ over arrays, it is in fact slightly convexly curvilinear. An excess of association over dispersion of alleles of like effect among the selection lines or duplicate gene interaction could be the cause (Jinks, 1956; Hill, 1964; Coughtrey and Mather, 1970). An excess of association would be expected for the genes controlling rate of growth, and for any character such as general sensitivity that is highly correlated with it, because of the past history of directional selection for extreme high and low scoring phenotypes.

The comparable analyses of specific sensitivity show that there are significant differences between arrays for the sum of $W r+\operatorname{Vr}(\mathrm{P}=0.05-0 \cdot 01)$ but equally significant differences for the difference, $W r-\operatorname{Vr}(\mathrm{P}=0 \cdot 05-0 \cdot 01)$. Furthermore, the sums are independent of the array means $(r=-0.0295)$. From these analyses it is clear that the non-additive variation is complex. It involves epistasis, the effects of correlated gene distributions or both in addition to dominance. The selection lines differ in their proportions of dominant to recessive alleles, but there is no evidence of an overall direction to the dominance. This is contrary to the evidence from the analysis of variance and presumably arises from the confounding effects of the more complex components of the non-additive variation.

The evidence for the more complex components of the non-additive variation comes from the differences in $W r-V r$ values over arrays. Examination of these values shows that the arrays of parents $2 \mathrm{LG}$ and $2 \mathrm{HP}$ are largely responsible for these differences. Their $W r-V r$ values are relatively large and negative in both replicates. Negative values of this magnitude imply either overdominance or pseudo-overdominance arising from either dispersion of directionally dominant alleles or complementary gene interactions (Jinks 1955, 1956; Mather 1967). True overdominance alone could not lead to the significant differences between arrays or the small or even positive values of $W r-V r$ observed for some arrays. Dispersion might, but since the parents $2 \mathrm{LG}$, and $2 \mathrm{HP}$ are the extreme phenotypes for specific sensitivity (table 4 ) they are more likely to show association of like alleles than dispersion and as we have already noted there is no evidence of directional dominance. The most likely explanation of the heterogeneity of $W r-V r$ values over arrays is, therefore, complementary gene interactions involving mainly parents $2 \mathrm{LG}$ and $2 \mathrm{HP}$.

We arrive at a similar conclusion if we compare the specific sensitivities of each of the 15 matings between the parental selections with those of their own pair of parents. For ten of the matings the sensitivities fall between those of their pairs of parents. For each of the remaining five, namely $2 \mathrm{LP} \times 2 \mathrm{~L}, 2 \mathrm{LG} \times 2 \mathrm{HP}, 2 \mathrm{~L} \times 2 \mathrm{HP}, 2 \mathrm{LG} \times 2 \mathrm{H}$ and $2 \mathrm{HP} \times 2 \mathrm{H}$ the sensitivity of the mating falls outside of its parental range. All but the first of these involves 2LG or 2HP as one of the two parent. The four matings have another characteristic in common. All the parents involved have negative specific sensitivities. Furthermore, all five matings have a large positive deviation from their respective midparent values. The inbred selections involved in these matings must be homozygous predominantly for 
alleles conferring negative sensitivities. Yet when combined in these five matings they give phenotypes which would be expected from genotypes with predominantly dominant alleles conferring positive sensitivities. Even the most extreme negative scoring parents such as 2LG and 2HP would have to be homozygous for some dominant positive alleles carried at different loci in the two parents of each of the matings. But to produce the large positive deviations between the sensitivities of the matings and the averages of their two parents the action of these dominant positive alleles must either be suppressed in the parents if frequent or augmented in the matings if rare. In other words, there must be some kind of complementary epistasis between the dominant alleles dispersed between the pair of parents.

\section{(v) Alternative analyses}

An alternative approach is to analyse the data from each of the four environments independently. From the replicate diallels the genetical control of rate of growth can be determined in each environment and any qualitative or quantitative effects of the different environments on this control detected.

TABLE 7

The analysis of the non-additive variation for rate of growth in the $6 \times 6$ diallel sets of matings in each of the four temperature environments

\begin{tabular}{|c|c|c|c|c|}
\hline & \multicolumn{4}{|c|}{ Environment } \\
\hline & $15^{\circ} \mathrm{C}$ & $20^{\circ} \mathrm{C}$ & $25^{\circ} \mathrm{C}$ & $30^{\circ} \mathrm{C}$ \\
\hline Heterogeneity of $(W r-V r)$ over arrays & n.s. & $*$ & n.s. & n.s. \\
\hline Correlation of $(W r+V r)$ and array mean & $-0 \cdot 603$ & -0.791 & -0.884 & -0.875 \\
\hline
\end{tabular}

In each of the four environments there is significant additive and nonadditive genetical variation. This has been analysed by the $W r, V r$ relationship with the results summarised in table 7 . From the relative consistency of the $W r-V r$ relationship over arrays and replicate diallels it is clear that non-allelic interactions and correlated gene distribution are not major contributors to the non-additive variation. The relationship between $\mathrm{Wr}$ and $V r$ is nevertheless convexly curvilinear rather than linear in all of the four environments. As already noted, the most likely causes are duplicate gene interactions and association between alleles of like effect, and as previously noted, the latter we would expect in any case from the divergent selection for high and low rates of growth. Once allowance is made for this there is no reason to believe that the non-additive gene action is other than dominance. From the correlation of $W r+V r$ and array mean over arrays any directional element in this dominance can be assessed. As this correlation is negative in every environment, the alleles conferring high growth rates must be more frequently dominant than their counterparts which confer low growth rates in every environment (table 7). This directional element, however, increases with the temperature and inspection of the data shows why this is so. The low selection 2LG behaves as though 
it has more dominant alleles than the high selection $2 \mathrm{HP}$ at $15^{\circ} \mathrm{C}$, but their positions are progressively reversed as the temperature rises while the other four selection lines retain their rank order over all temperatures (table 8) except for $2 \mathrm{H}$ and $2 \mathrm{HG}$ at $30^{\circ} \mathrm{C}$.

TABLE 8

Ranking of the six selection lines on the basis of their $(\mathrm{Wr}+\mathrm{Vr})$ values from the highest $(1)$ to the lowest $(6)$ proportion of dominant to recessive alleles for each of the four environments

\begin{tabular}{cllll} 
& \multicolumn{4}{c}{ Environment } \\
\cline { 2 - 5 } Rank order & $15^{\circ} \mathrm{C}$ & $20^{\circ} \mathrm{C}$ & $25^{\circ} \mathrm{C}$ & $30^{\circ} \mathrm{C}$ \\
1 & $2 \mathrm{LG}$ & $2 \mathrm{HG}$ & $2 \mathrm{HG}$ & $2 \mathrm{HP}$ \\
2 & $2 \mathrm{HG}$ & $2 \mathrm{HP}$ & $2 \mathrm{HP}$ & $2 \mathrm{H}$ \\
3 & $2 \mathrm{H}$ & $2 \mathrm{H}$ & $2 \mathrm{H}$ & $2 \mathrm{HG}$ \\
4 & $2 \mathrm{HP}$ & $2 \mathrm{LG}$ & $2 \mathrm{LP}$ & $2 \mathrm{LP}$ \\
5 & $2 \mathrm{LP}$ & $2 \mathrm{LP}$ & $2 \mathrm{LG}$ & $2 \mathrm{LG}$ \\
6 & $2 \mathrm{~L}$ & $2 \mathrm{~L}$ & $2 \mathrm{~L}$ & $2 \mathrm{~L}$
\end{tabular}

It will be recalled that $2 \mathrm{LG}$ and $2 \mathrm{HP}$ are the least temperature sensitive of the three low selections and three high selections, respectively. They are also the two selections most clearly implicated in the non-allelic interactions for specific sensitivity (Section 3.iv). Furthermore, matings involving these two selections show the greatest relative increases in specific sensitivity. We can now see why. At low temperatures the low growth rate of LG is dominant and the high growth rate of HP is recessive while at the higher temperatures the high growth rate of HP is dominant and the low growth rate of LG is recessive. Hence the matings involving them are among the slowest growing at low temperatures and among the fastest growing at higher temperatures although they are intermediate in average growth rate over all temperatures. They have, therefore, exceptionally high sensitivities to temperature relative to their mean growth rates and hence they have high specific sensitivities in spite of the relatively low specific sensitivities of their parents (Section 3.iii).

\section{Genetical architecture}

We have now examined rate of growth in a genetically replicated diallel set of matings between six selection lines in each of four environments. We have analysed the genetical control of rate of growth itself in each of these environments (Section 3.v), and converted the rate of growth of each mating in the four environments into two orthogonal components, one measuring mean performance over environments, the other, linear rate of change over environments (Section 3.ii). The latter has been partitioned into two components, general sensitivity, which is a linear function of mean performance itself and specific sensitivity which is independent of mean performance (Section 3.iii) and the genetical control of both components has been determined (3.iv). We are, therefore, now able to draw conclusions about the genetical architecture of rate of growth and of its interaction with temperature and about the genetical basis of the differences among the selection lines.

For rate of growth in each of the four environments and for general 
environmental sensitivity, which is a linear function of mean rate of growth over all four environments, there is directional dominance for faster growth and greater sensitivity, respectively. In selecting for a low rate of growth we have, therefore, been fixing mainly recessive alleles. This is consistent with the greater response observed on selecting for low (L) as opposed to high $(\mathrm{H})$ rate of growth in both poor $(\mathrm{P})$ and good $(\mathrm{G})$ environments and also with the fall in rate of growth observed on inbreeding isolate 2 (Connolly and Simchen, 1973).

Some features of the directional dominance for rate of growth differ between environments. When grown in the poorest environment $\left(15^{\circ} \mathrm{C}\right)$ all the selections made in the good environment $\left(30^{\circ} \mathrm{C}\right)$ display more dominant alleles than the corresponding selections made in the poor environment (table 8). Similarly, when grown in the best environment $\left(30^{\circ} \mathrm{C}\right)$ all the selections made in the poor environment display more dominant alleles than the corresponding selections made in the good environment. These results are again consistent with the more ready fixation of recessive alleles by selection. Thus more recessives for extreme rates of growth in poor environments $\left(15^{\circ} \mathrm{C}, 20^{\circ} \mathrm{C}\right)$ are expressed and are fixed by selection at $20^{\circ} \mathrm{C}$ than are expressed and fixed by selection at $30^{\circ} \mathrm{C}$ while more recessives for extreme rates of growth at $30^{\circ} \mathrm{C}$ are expressed and fixed by selection at $30^{\circ} \mathrm{C}$ than are expressed and fixed by selection at $20^{\circ} \mathrm{C}$. The superior performances of these selections in the temperature environments in which they are selected reported by Jinks and Connolly (1973) are due, therefore, to recessive alleles whose effects are fully expressed and fixed only in the selection environment. Two of the selection lines, $2 \mathrm{~L}$ and $2 \mathrm{H}$, which were selected for their overall performance in both poor and good environments (Connolly and Simchen, 1973) are, with one exception, consistently the most recessive of the three low and three high selections, respectively in every environment (table 8 ). This is again consistent with more recessive alleles conferring extreme rates of growth at both $20^{\circ} \mathrm{C}$ and $30^{\circ} \mathrm{C}$ being fixed in these selection lines.

Specific sensitivity is unique among the traits studied in that epistasis is a significant component of its genetical architecture (Section 3.iv). This epistasis is largely attributable to matings involving selections 2HP and 2LG and is at its greatest in the mating between this pair of selections. But even these epistatic relationships can be related to changing dominance relationships of the selections with changes in temperature (Section 3.v). For example, selection $2 \mathrm{HP}$, having been made in a poor environment, has more recessive alleles which are expressed in poor than in good environments, while selection 2LG, having been made in a good environment, has more recessive alleles which are fully expressed only in good environments. As a result the mating between them grows slower than average in poor environments and faster than average in good environments. Its rate of growth is, therefore, exceptionally sensitive to changes in temperature even though both of its parents are exceptionally insensitive.

To summarise, therefore, the genetical control of rate of growth and of its interaction with temperature is largely explicable in terms of additive and dominance gene action. The dominance is preponderantly in the direction of faster growth and greater temperature sensitivity. The interactions between rate of growth and temperature that are not simply related to differences in growth rate itself formally involve epistatic effects although 
these can be traced to changes in dominance relationships between fast and slow growth rate alleles with changes in temperature. The differences among the three low selections and among the three high selections that are primarily related to the environment of selection (Jinks and Connolly, $1973,1975)$ appear to be due to recessive alleles which are fully expressed only in the environment of selection.

Acknowledgments.-We are indebted to Dr G. Simchen for advice and encouragement during these experiments, to $\mathrm{Mr} \mathrm{P}$. J. Jinks for assistance with the analyses and to Professor $\mathrm{K}$. Mather for helpful discussions about the interpretation.

\section{REFERENCES}

CONNOLLY, v., AND SMMCHEN, G. 1973. Two-environment selection with inbreeding in Schizophyllum commune. Genet. Res., Camb., 22, 25-36.

COUGHTREY, A., AND MATHER, א. 1970. Interaction and gene association and dispersion in diallel crosses where gene frequencies are unequal. Heredity, 25, 79-88.

hayman, в. I. 1954. The analysis of variance of diallel tables. Biometrics, 10, 233-244.

HILL, J. 1964. Effects of correlated gene distributions in the analysis of diallel crosses. Heredity, 19, 27-46.

JiNks, J. L. 1954. The analysis of continuous variation in a diallel cross of Nicotiana rustica varieties. Genetics, 39, 767-788.

JnNKS, J. L. 1955. A survey of the genetical basis of heterosis in a variety of diallel crosses. Heredity, 9, 223-238.

JINKS, J. L. 1956. The $\mathrm{F}_{2}$ and backcross generations from a set of diallel crosses. Heredity, $10,1-30$.

JINKS, J. L., AND CONNOLLY, v. 1973. Selection for specific and general response to environmental differences. Heredity, 30, 33-40.

JINKs, J. L., AND CONNOLLY, v. 1975. Determination of the environmental sensitivity of selection lines by the selection environment. Heredity, 34, 401-406.

MATHER, K. 1967. Complementary and duplicate gene interaction in biometrical genetics. Heredity, 22, 97-103.

MATHER, K., AND Jinks, J. L. 1971. Biometrical Genetics. Chapman Hall, London.

SMMCHEN, G., AND JINKS, J. L. 1964. The determination of dikaryotic growth rate in the basidiomycete, Schizophyllum commune: a biometrical analysis. Heredity, 19, 629-649. 